\title{
Techno-economic Influence on Malaysia's Solar Thermal Installation for Heating Process
}

\author{
Anis Sabirin Baharom ${ }^{1}$, Nofri Yenita Dahlan ${ }^{2}$ \\ ${ }^{1}$ University Selangor (UNISEL), Faculty of Engineering and Life Sciences, Bestari Campus Jalan Timur Tambahan, \\ Bestari Jaya, Selangor, 45600, Malaysia \\ ${ }^{1,2}$ Universiti Teknologi MARA (UiTM), Electrical Engineering Faculty, Shah Alam, Selangor Darul Ehsan, \\ 40450, Malaysia
}

\begin{tabular}{l}
\hline \hline Article Info \\
\hline Article history: \\
Received May 9, 2018 \\
Revised Jul 2, 2018 \\
Accepted Jul 14, 2018
\end{tabular}

Keywords:

Solar Thermal Heating

System Dynamics

Techno-Economic

\begin{abstract}
This paper presents System Dynamics simulation and Techno-Economic analysis to estimate the techno-economic benefits and reliabilities of solar heating. The study focuses only on industrial heat process in Malaysia. The main objective of the current work was to investigate the solar thermal installation feasibility by Malaysian industrial heat process for next 20 years. The solar thermal installation was measured through the techno-economic feasibility (TEF) study by developing the TEF model using System Dynamics Simulation (SDS). Subsidy, net solar thermal cost, and NPV are used as economic influence factors. System performance, solar thermal life time, energy, solar fraction and size of collector area are used as technical influence parameters. Results have shown that the economic factor has a bigger influence on solar thermal installation capacity in Malaysia. The technical factors only contribute small percentage to the installation percentage. Policy maker could benefit from the outcomes obtained as a guideline.
\end{abstract}

Copyright $(2018$ Institute of Advanced Engineering and Science. All rights reserved.

Corresponding Author:

Anis Sabirin Baharom,

Faculty of Engineering and Life Sciences,

University Selangor (UNISEL),

Bestari Campus Jalan Timur Tambahan, Bestari Jaya, Selangor, 45600, Malaysia.

Email: anis@unisel.edu.my

\section{INTRODUCTION}

At present, Malaysia index of industrial production has expended by 3.0 percent as being compared to the previous month last year. The percentage mentioned was contributed by three sub-sectors. The subsectors mentioned are 1) electrical and electronic products, 2) petroleum, chemical, rubber and plastic and 3) non-metallic mineral, basic metal, and fabricated metal products. Each sub-sector contributes 5.7\%, 6.6\% and $5.1 \%$ expansion respectively [1]

In Malaysia, as per updated by Ministry of International Trade and Industry (MITI) last year, there are 14 manufacturing profiles such as chemical and petrochemical, automotive, wood based, textile apparel and footwear, rubber, electrical and electronics, machinery and equipment, aerospace, iron steel, cement, food, medical devices and pharmaceutical. There are a few policies have been established to help the development of industry in Malaysia. Ministry of Energy, Green Technology and Water (KHETTA) has reported that most of the energy related policies available are functions as promoting agent for energy efficiency and renewable energy for electricity supply. Meanwhile, National green technology policy is available for products application and development, equipment and system which able to minimizes and reduces the impact of human activities.

At present, numerous works have been done to investigate the energy and process industries on electricity energy usage [2]-[4]. However, little work has been carried out to investigate the heating energy 
usage in the small medium enterprises (SME). Therefore, a study on the heating installation capacity for SME is essential. A model to investigate the acceptance of Malaysian SME industries towards solar thermal technology as an alternative to current energy sources for the heating process was developed.

Recent work has focused on two main factors that may have an influence on the solar thermal installation capacity (STIC) in Malaysia. The research was conducted by developing a system dynamics model using TEF technique. The model was tested based on business as a usual scenario where the current setting was divided into two categories technical and economic such as solar fraction, energy for heating 40 gallons water, solar thermal life time, temperature level, level of radiation, solar efficiency, working days in a year, energy yield from evacuated tube collector (ETC), daily sun radiation, annual SME projection, subsidy, total cost and discount rate. Each parameter was set to the best value which has been identified from previous work or research. Monte Carlo simulation using excel is used for annual SME projection energy needed. This research aims to identify the economic and technical uncertainties which may influence the solar thermal installation in Malaysian's process SME. In the next section, the TEF and SDS are briefly reviewed.

The total cost for economic influence factor are contributed by fuel saving, cost of replacing the fuel system, cost of solar energy storage, cost for integration process, cost for solar looping and others cost. Fuel saving is depending on the installed area for collector and energy generated by $\mathrm{m}^{2}$ of the collector. Cost of replacing the fuel is the cost of work and equipment used for replacing the current system or integrating with solar thermal technology. Finally, others costs are the cost that may occur during the installation which includes the cost of designing and commissioning the system. At the moment, the solar thermal installation is eligible for subsidy under Green Technology Fund Scheme (GTFS).Solar radiation and temperature level for heating be part of the cause of system performance. Energy generated in a year is depending on system efficiency, annual solar yield from ETC, working days and hours of solar radiation best received.

\section{RESEARCH METHOD}

This research is carried out based on the business as usual (BAU) scenario. The objective of TEF is to identify the technical and economic feasibility for solar thermal installation for SME low temperature heating process in Malaysia. The reason for having this study is to find the effective way to overcome the doubt that most of the Malaysian Industries are having towards solar thermal heating technology [5]-[7]. In this paper, the TEF key factors influence the installation decision for Malaysian SME industries. The TEF was done using Vensim software where the simulation was carried out using SDS. The cores of the TEF data for the technical and economic component of the solar thermal heating technology are based on the previously completed project (Poultry Processing Malaysia PPNJ) [8].

Figure 1 shows simulation flow for TEF. The TEF was carried out by SDS. The SDS will generate percentage for each parameter such as technical influence, economic influence and the combination of technical and economic (techno-economic influence). Then, the percentage of techno-economic influence, the capacity installation will be determined for each year and accumulates for next 20 years.

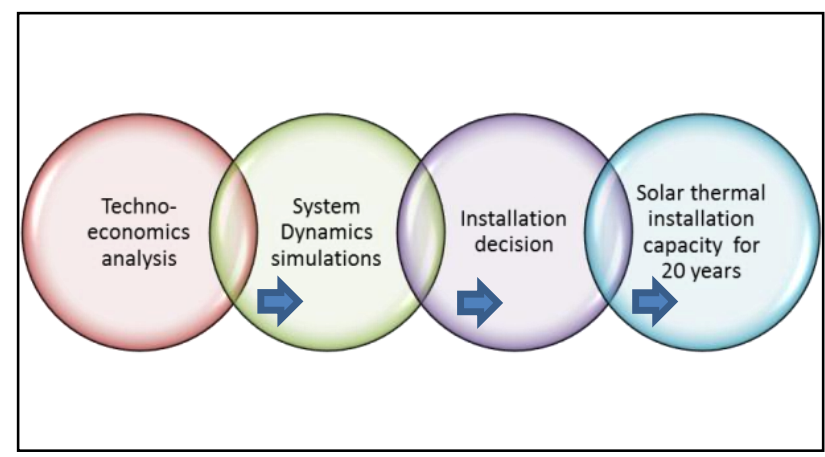

Figure 1. Simulation structure for techno-economic analysis Techno-Economic Feasibility (TEF)

TEF is a study that able to determine the technical and financial influence on the project implementation. It has a lot of benefits. Through the TEF study, the few outcomes can be determined such as market research, project cost estimation operating cost estimation, resource requirement, financial feasibility, and funding pattern suggestion. All issues mentioned are able to aid the policy maker to draw a proper incentive to boost the decision of installing the solar thermal technology. 
In 2015, the author [9], has used the techno-economic for solar drying system in Malaysia. The studies focused on payback period, net present value(NPV), life cycle saving (LCS) and life cycle costing fuel price. Most recently, the [10] uses the same method of assessment to identify the operating temperature for gas thermochemical energy storage system. Meanwhile in Australia [11], uses techno-economic and reliability method of assessment to study the economic characteristic of local manufactured on solar water heaters.

\subsection{System Dynamics}

In 1958, System Dynamics was introduced for information feedback characteristic of industry activity. It is not limited to industries it also can be used for medicine, engineering, environmental change, politics economic behavior, and other fields [12]-[16]. System Dynamics has been used for the TEF studies since it is a methodology to discover a complexity of the system and change over simulated time. It employs an output of systems thinking and focuses on building and analyzing model through stock and flow of the input and output. System Dynamics is able to address weaknesses in a causal loop diagram. The model developed by System Dynamics has the ability to distinguish between stock, flows, policy and management issues [17]. In this research, few stages of System Dynamics modeling process involved. The stages are; 1) problem conceptualization, 2) qualitative problem mapping, 3) model formulation, 4) model calibration, 5) model testing and finally 6) knowledge translation.

At stage 1, the selection of model boundary has been determined. In this study, the boundary of the model has been limited to SME process industries with the low temperature heating process. Besides that, the time limit also has been set to 20 years. At the second stage, causal loop diagram and stock and flow diagrams were developed. The parameters, quantitative causal relations, decision rules and the initial conditions have been specified in the third stage. For this stage, a system of differential equations with complex feedback relationships between variables was used. Next, in the 4th stage, the reference mode reproduction and matching of observed data point were performed. For model testing, the activities such as unit checking, problem domain test, and formal analysis were conducted. At the final stage, the learning environment was carried out to understand the outcome and the impact of the outcome.

\subsection{Techno-Economic}

In Malaysia, solar thermal technologies can be considered young technologies [18]. It is still in the development phase, where some of the SME industries have not been exposing to solar thermal heating technology. Hence, a technical and economic viability study of solar thermal heating technology is needed prior to the development phase. Through the study, the feasibility of economic and technical will be evaluated using thinking system which is known as system dynamics. Via the study, the improvement in economic and technical will be focused. The objective of having the study is to identify which parameter has a bigger influence on solar thermal installation in Malaysia's SME. This will benefit the policy maker to tailor the best solution to overcome the negative influence.

For technical matters, the analysis looks at the area needed for installation, anticipate the heating energy consumption, energy used for heating the water, solar fraction, solar thermal collector life time, system performance, and system efficiency. This data is used to predict future cash flows and a net present value (NPV). It is important to calculate the NPV and it needs to be greater than $0(>0)$ in order for the project to be doable or viable.

This analysis is useful for all investor and Malaysian government prior to investing on the technology for cost and environmental saving. The TEF study can be used as an input element to test the impact on Malaysian STIC for next 20 years.

\subsection{Mathematical Modeling}

All the data used in the studies are based on data collected by Standard and Industrial Research Institute of Malaysia (survey conducted by SIRIM) and Institute for Sustainable Technologies (AEE INTEC) under solar heat for an industrial process (SHIP). The TEF model is divided into three sub-models as follows 1) Technical influence, 2) Economic influence and 3) Solar thermal installation capacity (STIC). Sub-models and full model for stock and flow diagram for (a) technical influence, (b) economic influence, (c) STIC and TEF are shown in Figure 2. 


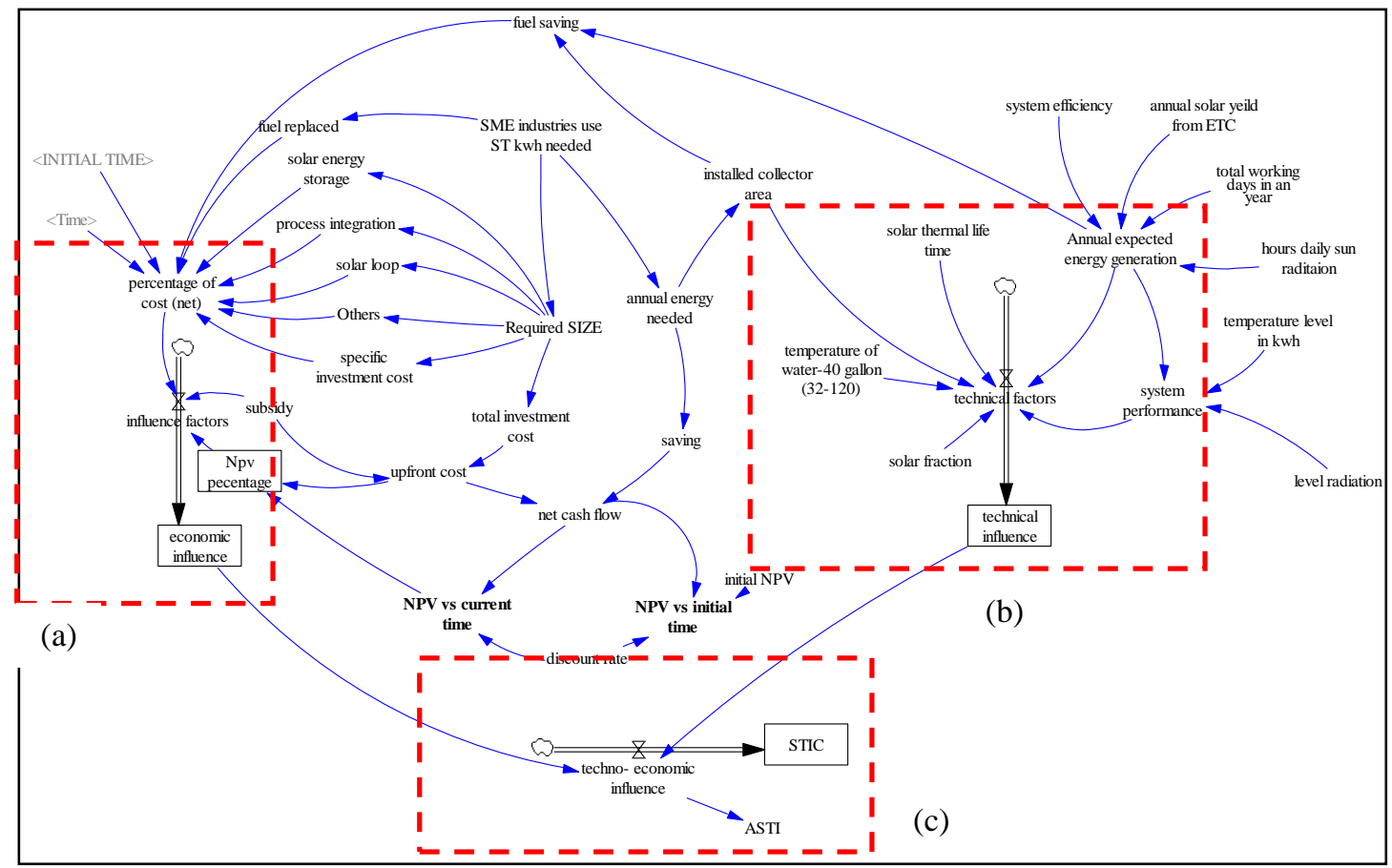

Figure 2. TEF Model

The TEF model is defined by the following expression:

Technical influence $=\int_{t 0}^{t_{20}}$ technical factor $d t+$ technical influence $t_{0}$

The technical influence is governed by the equation [1], where the technical influence is an accumulated percentage of technical factors which controlled by the system performance, expected energy generation (annually), solar thermal life time, installed collector area, solar fraction and temperature needed to heat 40 gallons of water.

Economic influence $=\int_{t 0}^{t_{20}}$ economic factor $\mathrm{dt}+$ economic influence $\mathrm{t}_{\mathrm{t}_{0}}$

Economic influence is determined by equation [2], where Economic influence is determined by the accumulation of the few influence factors such as NPV percentage, a current subsidy from green technology policy and the net cost of solar thermal heating (\%).

$$
\mathrm{STIC}=\int_{\mathrm{t}_{0}}^{\mathrm{t}_{20}} \text { technoeconomic influence decision } \mathrm{dt}+\mathrm{STICt}_{0}
$$

Finally, the STIC in Malaysia prediction for 20 years is governed by equation [3]. Figure 2(c) shows the connection between the technical and economic influence on the decision taken for STIC. Any changes to the feedback structure may cause changes to the behavior of installation capacity.

Specific forecast for energy needed by SME heating process industries was simulated by Monte Carlo simulation using excel. The Monte Carlo simulation was carried out based on the assumption made from the Malaysia energy balance 2015. The assumptions were made based on $70 \%$ of final energy demand by industrial sector is used for heating process and only $10 \%$ out of $70 \%$ has potential to convert to solar thermal heating technology.

\section{RESULTS AND ANALYSIS}

In view of the results obtained as shown in Table 1, the percentage of two outputs STIC and ASTIC were monitored for over twenty years. The results showed that the techno-economic influence, took almost 17 years for the investor to have confidence (50\%) on the solar heating technology. This suggested that improved policy or new policy for solar thermal is needed since the current policy is not facilitating the solar Techno-economic Influence on Malaysia's Solar Thermal Installation for Heating ... (Anis Sabirin Baharom) 
thermal technology growth in Malaysia. This may lead, the GEF and UNIDO project target's in reducing GHG Emissions from solar thermal utilization in Malaysian Industry [19] be unfeasible or useless. The annual solar thermal installation (ASTI) takes almost 8 years to increase the kWh number for solar thermal technology installation from $10 \mathrm{~kW}$ to $20 \mathrm{~kW}$ annually under business as usual (BAU) scenario. This scenario shows that the low installation may happen due to the low awareness and the less support given by the government or financial institution.

Table 1. The results of the TEF model

\begin{tabular}{cccc}
\hline Time $($ year $)$ & ASTI $(\mathrm{kWh})$ & STIC $(\mathrm{kWh})$ & Techno-economic influence $(\%)$ \\
\hline 1 & 10 & 10 & 0.286144 \\
2 & 10 & 10 & 0.618159 \\
3 & 10 & 30 & 1.09974 \\
4 & 10 & 70 & 2.43811 \\
5 & 10 & 150 & 6.00753 \\
6 & 10 & 310 & 6.61608 \\
7 & 10 & 630 & 9.22825 \\
8 & 20 & 1270 & 10.838 \\
9 & 20 & 2560 & 11.9386 \\
10 & 20 & 5140 & 13.2817 \\
11 & 20 & 10300 & 14.2858 \\
12 & 30 & 20620 & 15.4745 \\
13 & 30 & 41270 & 16.9374 \\
14 & 40 & 82570 & 20.4091 \\
15 & 40 & 165180 & 24.9908 \\
16 & 50 & 330400 & 29.1624 \\
17 & 70 & 660850 & 38.34 \\
18 & 200 & $1.32177 \mathrm{e}+006$ & 58.1814 \\
19 & 300 & $2.64374 \mathrm{e}+006$ & 64.47 \\
20 & 700 & $5.28778 \mathrm{e}+006$ & 83.9479 \\
\hline
\end{tabular}

The view of the results obtained from Figure 3 (a) \& (b), the economic factor percentage was bigger than a technical factor. It can be seen that the increase of economic factor is mainly due to the installation cost and financial support. However, no obvious trend of the technical parameter can be seen for any changes of STIC. This is due to the technical factor contributors are uncontrollable such as solar radiation, working hours and energy needed for heating water up to certain temperature.

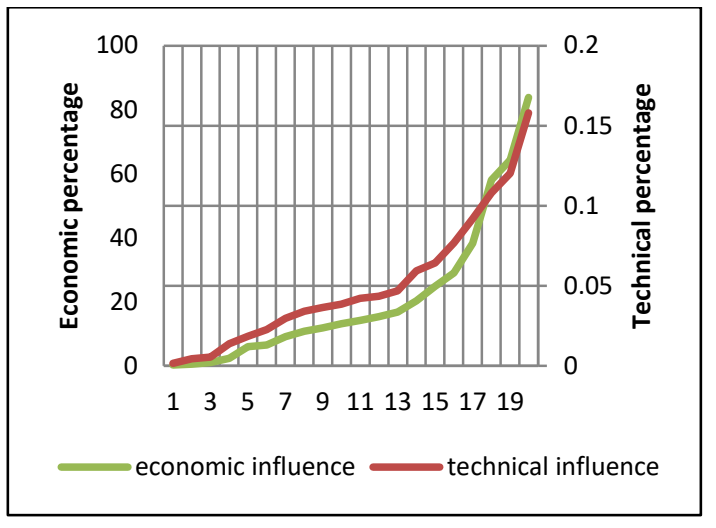

Figure 3(a). Comparison of economic and technical influence percentage

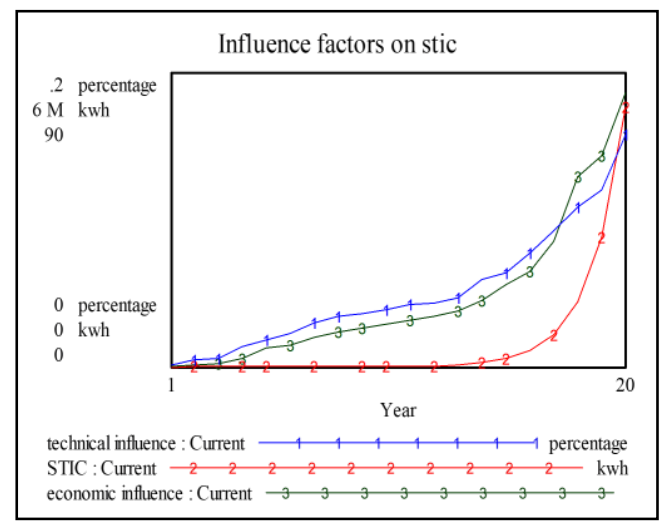

Figure 3(b). Economic and Technical influence on STIC

The trends for the influence of the NPV and Net cost of the project are shown in Figure 4 (a) and (b). The net cost has a greater influence on ASTI with current subsidy remain constant at $80 \%$. No significant stimulation between NPV and ASTI was evident. There were minimal influences of a technical factor on STIC and ASTI due to parameters in technical factor beyond human control capability such as solar radiation and hours of sun radiation. Overall, the improvement in installation cost, as well as other technical 
parameters such as solar fraction and system efficiency, should show good agreement with the STIC and ASTI by using proposed TEF model.

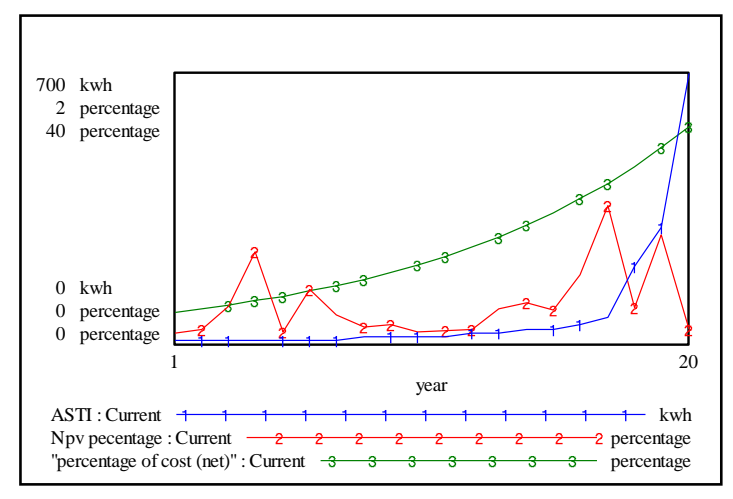

Figure 4(a) The Impact of NPV and Net cost on ASTI under BAU scenario

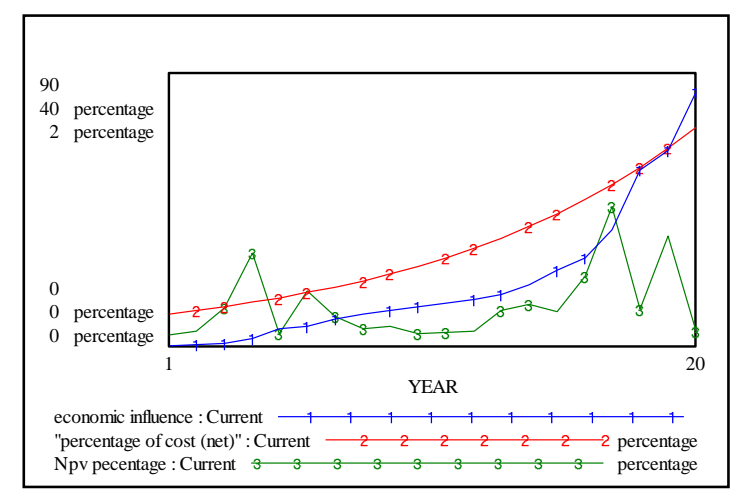

Figure 4(b) The Impact of NPV and Net cost Economic influence under BAU scenario

\section{CONCLUSION}

In this work, a TEF model was developed to determine the techno-economic influence on STIC for heating process industries in Malaysia. The results have revealed that the economic factor does have great influence on STIC compared to technical parameters. Therefore, for the effect of economic influence on STIC for process industries can be reduced by developing the new policy specific for SME industries. For further works, another model of support mechanism from government and the financial institution is suggested to be taken into account in order to develop the new policy to boost the STIC. It is considered that this TEF model can provide a guideline to policy maker to develop a solar thermal policy for Malaysian SME process industries.

\section{REFERENCES}

[1] D. of S. Malaysia, "Malaysia Index of Industrial Production," 2018. [Online]. Available:

https://www.dosm.gov.my/v1/index.php?r=column/ctwoByCat\&parent_id=89\&menu_id=SjgwNXdiM0JIT3Q2TD BlWXdKdUVldz09.

[2] S. S. A. Wahid, M. S. Ramli, Z. A. Noorden, K. K. Hassan, and S. A. Azli, “A review on highlights and feasibility studies on solar energy utilization in Malaysia," in AIP Conference Proceedings, 2017.

[3] R. Kardooni, S. B. Yusoff, F. B. Kari, and L. Moeenizadeh, "Public opinion on renewable energy technologies and climate change in Peninsular Malaysia," Renew. Energy, 2018.

[4] P. D. Gerhard Stryi-Hipp, Werner Weiss, Daniel Mugnier, "Strategic Research Priorities for Solar Thermal Technology," 2012.

[5] B. Nofri, Y. Dahlan, and M. F. Ismail, "Solar Thermal Policy in Malaysia: Potential Barriers and Action Plans For The Industry," Policy Brief, Shah Alam, 2015.

[6] A. S. Baharom and N. Y. Dahlan, "System Dynamic Approach for Long-Term Solar Thermal Installed Capacity for Malaysian Industries," Indones. J. Electr. Eng. Comput. Sci., vol. 6, no. 3, pp. 572-582, 2017.

[7] A. S. Baharom and N. Y. Dahlan, "Solar thermal heating acceptance among Malaysian industries using system dynamics," Indones. J. Electr. Eng. Comput. Sci., vol. 8, no. 2, pp. 375-381, 2017.

[8] AEE INTEC., "Database for applications of solar heat integration in industrial processes." [Online]. Available: http://ship-plants.info/solar-thermal-plants/250-poultry-processing-malaysia-ppnj-malaysia?country=Malaysia.

[9] A. Fudholi, K. Sopian, M. Gabbasa, B. Bakhtyar, M. Yahya, M. Ha, and S. Mat, "Techno-economic of solar drying systems with water based solar collectors in Malaysia : A review," Renew. Sustain. Energy Rev., vol. 51, pp. 809820, 2015.

[10] A. Bayon, R. Bader, M. Jafarian, L. Fedunik-hofman, Y. Sun, J. Hinkley, S. Miller, and W. Lipi, “Technoeconomic assessment of solid e gas thermochemical energy storage systems for solar thermal power applications," Energy, vol. 149, pp. 473-484, 2018.

[11] S. Rezvani, P. A. Bahri, T. Urmee, G. F. Baverstock, and A. D. Moore, "Techno-economic and reliability assessment of solar water heaters in Australia based on Monte Carlo analysis," Renew. Energy, vol. 105, pp. 774785, 2017.

[12] R.G.COYLE, System Dynamics Modelling A Practical Approach. Chapman and Hall, 1996.

[13] M. Saleh, R. Oliva, C. Erik, and P. I. Davidsen, "A comprehensive analytical approach for policy analysis of system dynamics models,” vol. 203, pp. 673-683, 2010. 
[14] S. Wang, L. Xu, F. Yang, and H. Wang, "Science of the Total Environment Assessment of water ecological carrying capacity under the two policies in Tieling City on the basis of the integrated system dynamics model," vol. 472, pp. 1070-1081, 2014.

[15] A. Barisa, F. Romagnoli, A. Blumberga, and D. Blumberga, "Future biodiesel policy designs and consumption patterns in Latvia : a system dynamics model," vol. 88, 2015.

[16] H. Haghshenas, M. Vaziri, and A. Gholamialam, "Evaluation of sustainable policy in urban transportation using system dynamics and world cities data : A case study in Isfahan," vol. 45, pp. 104-115, 2015.

[17] J. D.Sterman, Business Dynamics -System Thinking and Modeling for a Comples World. Irwin Mc Graw-Hil, 2000.

[18] N. Yenita Dahlan and M. Fauzi Ismail, "A Review On Solar Thermal Technologies For Low And Medium Temperature Industrial Process Heat."

[19] Unido Malaysia, "Term of Reference Project 120264-Establishment of the National Solar Thermal Roadmap for Malaysian Industry," 2016. 